\title{
Classicismo e forma no pensamento estético de Schopenhauer
}

\author{
Classicism and form in Schopenhauer's aesthetical thinking
}

\author{
Márcio Benchimol \\ Doutor em Filosofia pela Unicamp \\ Professor de Estética e Filosofia da Arte do Departamento \\ de Filosofia da Unesp - Campus de Marília, SP. \\ E-mail: benchimolbarros@gmail.com
}

Resumo: Tendo por base um exame do papel desempenhado pela noção de forma no pensamento estético de Schopenhauer, o texto procura avaliar o grau de proximidade existente entre este pensamento e as ideias estéticas do classicismo alemão, recorrendo, para tanto, a um estudo comparativo entre as concepções de Johann Winckelmann e as reflexões schopenhauerianas sobre a arte e o belo.

Palavras-chave: Classicismo alemão; Forma; Winckelmann.

Abstract: Based in an investigation about the role played by the notion of form in Schopenhauer's aesthetical thinking, the present text tries to evaluate the degree of proximity which that thinking reveals relatively to the ideas of german classicism. For that sake, the author undertakes a comparative study between the conceptions of Johann Winckelmann and Schopenhauer's reflections on art and beauty.

Keywords: German classicism; Form; Winckelmann.

No início de sua "Metafísica do Belo", Schopenhauer distingue claramente a disciplina de que a obra trata em relação à estética. "A estética", diz ele, "relaciona-se com a metafísica do belo como a física se relaciona com a metafísica da natureza. A estética ensina o caminho pelo qual o efeito do belo é atingido, dá regras às artes, segundo as quais elas devem criar o belo“. Já a metafísica do belo, “...investiga a essência íntima da beleza...“' . Com isso dá o filósofo a entender que suas reflexões sobre a arte e a beleza pretendem fornecer uma interpretação filosófica sobre o significado metafísico das mesmas, dando já como estabelecido um certo conhecimento empírico e prático do belo, ou seja, uma estética. Porém, à época em que Schopenhauer elabora suas concepções sobre arte e beleza, há, não uma, mas duas estéticas em pleno vigor na Alemanha, e, de fato, duas estéticas antagônicas: a romântica e a do

\footnotetext{
${ }^{1}$ SCHOPENHAUER, A. Metafísica do Belo. São Paulo: Ed. Unesp, 2001, p.24.
} 
classicismo alemão. Caberia então a pergunta sobre qual das duas estaria sendo tacitamente pressuposta pelas reflexões schopenhauerianas sobre a arte.

Mas nem a "Metafísica do Belo" nem tampouco o terceiro livro de "O Mundo como Vontade e Representação" (primeiro volume) apresentam uma tomada de posição explícita entre românticos e classicistas. Ou melhor: não deixam vislumbrar qualquer indício sequer da existência da contenda! Ficaria então a critério de cada um louvar ou deplorar a soberana auto-suficiência de um filósofo que, escrevendo sobre estética entre 1818 e 1820, se sinta no direito de ignorar solenemente a oposição que, já havia décadas, tão febrilmente agitava a arte e a estética alemãs. Mas, olhando-se mais de perto, percebe-se que Schopenhauer de fato não a ignora, e penso mesmo que toma em sua obra máxima uma clara posição no debate, posição essa que - apesar de clara - se anuncia de maneira peculiarmente oblíqua já na forma como o filósofo lida com as ideias provenientes dos partidos litigantes: simplesmente não dá voz a um deles!

Com efeito, o terceiro livro de "O Mundo como Vontade e Representação" não menciona nem teses nem autores românticos, com a exceção de Kleist, de quem cita curta passagem poético-metafórica ${ }^{2}$, a qual não guarda qualquer relação com a natureza do debate em questão. Isto não parece ter sido nenhuma casualidade, pois a mesma situação se repete no restante dos textos schopenhauerianos especificamente estéticos, nos quais, dentre os expoentes do movimento romântico, apenas Tieck e os irmãos Schlegel merecem breves referências ${ }^{3}$, ambas, porém, igualmente irrelevantes do ponto de vista da discussão estética acima aludida. O único escritor alinhado às ideias estéticas românticas do século XIX alemão a receber menção claramente aprobatória, e em verdade mais de uma vez, de parte de Schopenhauer, é Jean Paul. Esta, porém, é uma figura reconhecidamente ambígua, no que se refere à oposição entre classicismo e romantismo: transitando entre os dois polos da querela, pode-se ver em Jean Paul, sob

\footnotetext{
${ }^{2}$ Cf. SCHOPENHAUER, WWV I/MVR I, § 50, p. 284 [318]. Obs: em se tratando do primeiro volume de O Mundo como Vontade e como Representação, as versões apresentadas no corpo do texto geralmente correspondem à tradução de Jair Barboza (Ed. Unesp. 2005). Nos casos em que minha versão difere desta tradução, e apenas nestes casos, apresento o original em nota.

${ }^{3}$ Ambas as passagens estão nos Vereinzelte, jedoch systematisch geordnete Gedanken, que, juntamente com a seção Einige Verse, compõem o segundo volume de Parerga e Paralipomena. Tieck é mencionado em nota a uma passagem do capítulo XXIII, Über Schrifttstellerei und Stil, e os irmãos Schlegel são aludidos rapidamente no capítulo XIX, Zur Metaphysik des Schönen und Aesthetik, (SCHOPENHAUER, A. P/P, p.549 e p.479, respectivamente).
} 
vários aspectos, também um defensor de princípios clássicos ${ }^{4}$. Precisamente neste sentido, aliás, deixa-se interpretar o elogio que Schopenhauer lhe faz. No capítulo 31 dos "Complementos ao Terceiro Livro" (WWV II/MVR II), louva-lhe o filósofo a objetividade (em sentido schopenhaueriano) de suas descrições da natureza, comparando-o, neste particular a Goethe, para mais adiante aprovar sua caracterização da Besonnenheit como característica fundamental do gênio, em Vorschule der Aesthetik ${ }^{5}$.

Apenas em uma única passagem de seus textos estéticos, consente Schopenhauer em fazer menção explícita à querela entre românticos e neoclássicos, a saber, no capítulo 37 dos "Complementos ao Terceiro Livro", denominado Zur Aesthetik der Dichtkunst. E nessa passagem se exprime explicitamente uma clara preferência pela estética clássica. A poesia clássica, afirma, contém verdade e correção ilimitadas, enquanto que à romântica cabe apenas limitadas verdade e correção, o que ocorre pelo fato de que aquela faz valer apenas “...motivos puramente humanos, reais e naturais", enquanto que esta introduz em si motivos "...artificiosos, convencionais e imaginários...". A estes pertencem os motivos oriundos...

... do mito cristão como também os dos excêntricos e fantásticos códigos de honra cavalheirescos, os ultrapassados e ridículos motivos germânico-cristãos da veneração das mulheres e por fim os delirantes e supralunares motivos do arrebatamento amoroso hiperfísico ${ }^{6}$.

Muito embora a comparação se dê apenas no campo da criação poética, mostrase ela perfeitamente extensível a outros campos do fazer artístico, uma vez que o contraste - aqui tornado fator decisivo - entre, por um lado, a naturalidade e simplicidade clássicas e, por outro, a exaltada imaginação romântica, com seu gosto pelo metafísico e pelo fantástico, e seu constante apelo às tradições cristãs e medievais, é um dos mais bem reconhecidos aspectos da oposição entre as duas escolas estéticas. $\mathrm{O}$ próprio Schopenhauer estimula essa extensão quando, ao fim da passagem mencionada,

\footnotetext{
4 Albert Meier, por exemplo, o classifica, juntamente com Kleist e Hölderlin, como um dos casos problemáticos da relação classicismo-romantismo (Cf. MEIER, A. Klassik-Romantik, Stuttgart, Reclam, 2008, capítulo Klassisch-romantische Problemfälle).

${ }^{5}$ SCHOPENHAUER, A. WWV II/MVR II, pp. 432-435.

6 “ ...dahin gehören die aus dem Christlichen Mythos stammenden, sodann die des ritterlichen, überspannten und phantastischen Ehrenprincips, ferner die der abgeschmackten und lächerlichen christlichgermanischen Weiberverehrung, endlich die der faselnden und mondsüchtigen hyperphysischen Verliebtheit”. (SCHOPENHAUER, A. WWV II/MVR II, Kap. 37, pp. 490).
} 
sugere que a oposição que acaba de fazer notar no campo da poesia é análoga àquela que se estabelece “... entre a arquitetura grega e a gótica”, as quais, como é sabido, são paradigmas da beleza arquitetônica respectivamente para clássicos e românticos.

Esta tomada de posição no segundo volume de $O$ Mundo como Vontade e Representação nos auxilia a compreender uma particularidade do terceiro livro do primeiro volume da obra: em contraste com o que ocorre em relação aos românticos, abundam ali as alusões a representantes do classicismo, bem como a suas ideias, com as quais Schopenhauer reiteradamente se põe de acordo. Uma exceção pareceria ser uma passagem de seu quinquagésimo capítulo, em que Schopenhauer, após apresentar suas considerações sobre o sentido e o valor da alegoria em arte, permite-se fazer um breve comentário em que marca sua diferença face a Winckelmann, no tocante a este particular. Afirma o filósofo ser sua convicção a este respeito totalmente contrária à do eminente esteta e historiador da arte, que indica como fím último da arte a “...exposição de conceitos universais e coisas não sensíveis" 7 . "A cada um é permitido escolher o próprio juízo", prossegue, conciliador, o filósofo, para afirmar-nos logo em seguida que semelhantes opiniões de Winckelmann, “...concernentes à metafísica do belo, propriamente dita...", tornam-lhe clara a verdade de que “...alguém pode ter a mais acentuada receptividade e o mais correto juízo sobre o belo artístico, sem que esteja, porém, em condições dar uma explicação abstrata e genuinamente filosófica sobre a essência do belo e da arte..." .

Vê-se então que o desacordo de Schopenhauer em relação a Winckelmann situase, segundo o próprio filósofo, apenas no campo da metafísica do belo propriamente dita, mas não no da experiência estética concreta. Neste domínio, reconhece-lhe Schopenhauer nada menos que “...a mais acentuada receptividade e o mais correto juízo...". No plano do conhecimento puramente intutivo, no qual precisamente se dá a experiência estética, Winckelmann seria então autoridade inconteste, autoridade esta que apenas pode e deve ser colocada em questão no que respeita à fundamentação metafísico-filosófica desta experiência. Mas é também verdade que um teórico da arte, stricto sensu, não está obrigado a fornecer tal sorte de fundamentação, sendo tão

\footnotetext{
${ }^{7}$ SCHOPENHAUER, A. WWV I/MVR I, § 50, p. 283 [317].

${ }^{8}$ Idem, ibidem. No original: "Nur wurde mir, bei diesen und ähnlichen, die eigentliche Metaphysik des Schönen betreffenden Ansichten Winckelmanns, die Wahrheit sehr deutlich, daß man die größte Empfänglichkeit und das richtigste Urtheil über das Kunstschöne haben kann, ohne jedoch im Stande zu seyn, vom Wesen des Schönen und der Kunst abstrakte und eigentlich philosophische Rechenschaft zu geben..." O destaque na versão apresentada é de minha autoria.
} 
arbitrário dele exigi-la como exigir de alguém que em sua conduta demonstra o mais claro discernimento ético, que seja capaz de fundamentar filosoficamente essa conduta 9 .

Winckelmann é, no terceiro livro de "O Mundo como Vontade e Representação", o esteta a quem o filósofo mais recorre. Seu nome aparece em seis contextos diferentes, em que é citado ou comentado a partir do que parece ser uma edição de suas obras completas, da qual Schopenhauer utiliza explicitamente três volumes (primeiro, sexto e sétimo, sendo que, no caso do primeiro, há referências que parecem provir de textos diferentes $)^{10}$.

Logo em seguida ao nome de Winckelmann, ainda segundo o critério quantitativo, vemos surgir o do mais célebre dos seus seguidores. De fato, Goethe é mencionado em maior número de contextos em $O$ Mundo como Vontade e como Representação I em comparação a Winckelmann, mas em apenas quatro deles seu nome aparece ligado diretamente a questões de natureza teórica em estética, o que o torna o segundo teórico da arte mais citado na obra. Nesta, aliás, demonstra Schopenhauer também significativo contato com outras obras e publicações diretamente ligadas ao classicismo alemão, e em particular ao de extração weimarana. No contexto da discussão sobre o Laocoonte, por exemplo, expõe com propriedade a posição de Lessing, cita os Römische Studien, de Fernow, mencionando, ao lado de um artigo goetheano nos Propyläen (periódico editado por Goethe, também citado em outra ocasião), um artigo de Hirt em Die Horen (revista inicialmente editada por Schiller e posteriormente também por Goethe $)^{11}$.

Tais são fatos de natureza meramente estatística e podem ser confirmados por um simples exame superficial do terceiro livro de $O$ Mundo como Vontade e como Representação I. Mas um estudo um pouco mais atento do texto não deixará de descobrir que Winckelmann está presente também onde não é nomeado, como também que as concepções estéticas características do classicismo alemão em geral encontram

\footnotetext{
${ }^{9}$ Eis a sequência imediata do trecho reproduzido na nota anterior: “...eben wie man sehr edel und tugendhaft seyn und ein sehr zartes, mit der Genauigkeit einer Goldwaage bei den einzelnen Fällen entscheidendes Gewissen haben kann, ohne deshalb im Stande zu seyn, die ethische Bedeutsamkeit der Handlungen philosophisch zu ergründen und in abstracto darzustellen.” Idem, ibidem.

${ }^{10}$ Os contextos em que o nome de Winckelmann é citado no terceiro livro de WWV I/MVR I são: $§ 45$, pp. 264 [299] e 265 [300]; § 46 pp. 267 [302] e 270 [305]; § 50, p. 283 [317] e § 51, p. 290 [325]. As citações das obras completas do esteta estão às páginas 264 [299] e 283 [317] (vol. 1); 267 [302] (vol. 7) e 270 [305] (vol. 6).

${ }^{11}$ Cf, SCHOPENHAUER, A., WWV I/MVR I, pp 267, 268 [302, 303], para a exposição de Lessing; 268 [303], para Fernow e Hirt (em Die Horen) e Goethe (em Propyläen); A outra citação de Goethe nos Propyläen está à página 269 [304].
} 
claro eco nas exposições schopenhauerianas. Uma tal investigação sobre a presença do elemento clássico no pensamento estético de Schopenhauer poderá seguramente seguir os mais variados caminhos, mas não poderá eximir-se de realizar um exame atento do papel desempenhado pelo conceito de forma neste pensamento. É a este exame que gostaria de dedicar o presente estudo, ainda que de maneira preliminar.

De fato, o conceito de forma resume e sintetiza em si alguns dos mais básicos preceitos da estética do classicismo alemão. Idéias como unidade, totalidade, harmonia, auto-referencialidade e equilíbrio encontram ali seu ponto de entrelaçamento, de tal maneira que se torna praticamente impossível definir-se a noção classicista de beleza sem o concurso deste conceito. Quando Karl Philipp Moritz define o belo como algo “...em si mesmo perfeito, que, portanto, perfaz um todo...” está ele dando expressão à própria concepção clássica de forma, pois, como formula Albert Meier, “...a arte clássica se apoia totalmente no belo, no sentido da perfeição da forma" ${ }^{12}$. Em sua obra Klassik - Romantik, distingue o estudioso a estética do classicismo pela exigência de que os produtos artísticos possuam o caráter de uma totalidade encerrada sobre si mesma $^{13}$. A forma clássica seria pensada como princípio ordenador pelo qual uma multiplicidade de elementos se converte em uma unidade que repousa harmonicamente em si mesma, sendo, justamente por isso, dotada de beleza.

Tal sentido do conceito de forma já se estabelece na obra inaugural do classicismo alemão, as Reflexões sobre a imitação das obras gregas na pintura e na escultura $^{14}$, de Winckelmann, em que a forma já se destaca como necessária portadora da beleza. De fato, adjetivos denotadores de qualidades estéticas, como "bela" e "sublime", vêem-se ali referidos constantemente ao substantivo "forma" 15 . O termo forma também aparece ligado ao adjetivo "nobre", 16 , no sentido ao mesmo tempo ético e estético que Winckelmann lhe empresta, ou seja: no sentido daquela "nobre simplicidade", que, ao lado da "grandeza serena" o autor aponta como régia propriedade da estatuária grega. No texto winckelmanniano, aliás, a noção de "simplicidade" se liga

\footnotetext{
12 MEIER, A., op. cit (ver nota 4), p. 28. Citação de Moritz, apud MEIER, p. 139.

${ }^{13}$ Cf. MEIER, op.cit, p.32: "O classicismo concentra-se ... em uma estética de obras (Werk-Ästhetik) para a qual o que importa é o auto-encerramento (Geschlossenheit) e a totalidade (Ganzheitlichkeit) de seus produtos."

${ }^{14}$ WINCKELMANN, J. "Gedanken über die Nachahmung der griechischen Werke in der Malerei und Bildhauerkunst", in Winckelmanns Werke in einem Band, Berlin und Weimar, Aufbau, 1969.

${ }^{15}$ Cf. WINCKELMANN, J. Op.cit., p. 4 ("Das Wachstum der schönen Form...”) e p.12 (“...durch Hilfe der ihm beständig gegenwärtigen erhabenen Formen").

${ }^{16}$ Cf. op.cit., p. 3: “...die frühzeitigen Leibesübungen aber gaben dieser Bildung die edle Form.”
} 
conceitualmente à própria concepção de forma, tal como a apresentamos acima, pois remete sobretudo às idéias de unidade e harmonia do todo (da obra de arte ou do objeto natural), de perfeita e necessária interligação das partes, assim como à da imediata apreensão intuitiva destas unidade e harmonia pela contemplação estética. Aquilo que confere tais qualidades às obras escultórica clássicas é aquilo que Winckelmann identifica como o principal objetivo do artista grego, ou seja, o contorno, cujo conceito está em evidente conexão com o da forma escultórica. "O mais nobre contorno", diz o autor, “...unifica e circunscreve todas as partes da mais bela natureza e das belezas ideais nas figuras dos gregos..."17. É ele, pois, que dá unidade à obra ao determinar sua configuração espacial, ou seja, sua forma. "O contorno magistral” (“der meisterhafte Kontur") traça os limites dentro dos quais a obra de arte grega se mostra justamente como totalidade simples, perfeitamente encerrada em si mesma, criando assim aquele nobre distanciamento pelo qual ela se destaca em face do mundo circundante, impondose à consideração admirada e serena do contemplador.

Mas as mútuas implicações entre as idéias de beleza, forma, simplicidade e unidade harmônica do todo encontram-se já bem mais claramente estabelecidas na celebrada História da Arte da Antiguidade, nomeadamente no capítulo intitulado "Von der Kunst unter den Griechen" (quarto capítulo da primeira parte da obra) ${ }^{18}$. É ali, por exemplo, que Winckelmann, em trecho de clara inspiração neoplatônica, afirma ser o conceito de beleza como um espírito apartado da matéria que busca incessantemente criar belas obras a partir da imagem da primeira criatura racional concebida pelo intelecto da divindade:

As formas de tal imagem são simples e sem descontinuidade, e nesta unidade são múltiplices, e por isso são elas harmônicas; da mesma maneira que um som doce e agradável é produzido por corpos cujas partes são isomorfas (gleichförmig). Pela unidade e simplicidade, toda

\footnotetext{
17 Idem, p. 13: "Der edelste Kontur vereinigt oder umschreibt alle Teile der schönsten Natur und der idealischen Schönheiten in den Figuren der Griechen, oder er ist vielmehr der höchste Begriff in beiden. ” 18 WINCKELMANN, J. Geschichte der Kunst des Altertums, Weimar, Verlag Hermann Böhlaus Nachfolger, 1964. À página 123 da obra, por exemplo, lemos: “...diese Begriffe [der Schönheit] bestehen teils in Maßen und Verhältnissen, teils in Formen, deren Schönheit der ersten griechischen Künstler Absicht war, wie Cicero sagt: diese bilden die Gestalt, und jene bestimmen die Proportion. " Um pouco adiante, refletindo sobre certas obras pictóricas em que a forma humana apresenta semelhança com a de animais, diz o autor: “...je stärker diese Ähnlichkeit [mit den Tieren] an einigen Teilen ist, desto mehr weicht die Form von den Eigenschaften unsers Geschlechts ab, und es wird dieselbe teils ausschweifend, teils übertrieben, wodurch die Harmonie unterbrochen und die Einheit und Einfalt gestört wird, als worin die Schönheit besteht...".
} 
beleza se torna sublime (erhaben), assim como tudo o que fazemos e dizemos: pois aquilo que em si é grande, torna-se sublime, se executado e exposto com simplicidade..$^{19}$

Semelhante concepção da bela forma como unidade simples em que uma multiplicidade de elementos sensíveis oferece-se imediatamente à percepção como um todo harmônico é apresentada, três décadas depois, de maneira bem mais abstrata, nas cartas relacionadas ao projeto Kallias, de Schiller. Na carta a Körner de 8 de fevereiro de 1793, define ele, deixando claramente ecoar suas recentes leituras kantianas: "Todas as representações são um múltiplo (ein Mannigfaltiges) ou matéria (Stoff). A maneira de ligação deste múltiplo é sua forma (Form)" "20 "Bela...", especifica, porém, na carta seguinte, "chama-se uma forma que explica a si mesma; explicar a si mesma significa, entretanto..., explicar-se sem auxílio de um conceito" ${ }^{21}$. A percepção da beleza prescinde de conceitos porque nela não são buscados conhecimentos. A bela forma é apreciada em si mesma e por si mesma, e não em relação a um objeto de que seria a mera aparição, e muito menos a outros objetos que com ele estivessem em relação, pois em ambos os casos seria necessário a interveniência de conceitos. Já sua autoexplicabilidade deriva de sua absoluta coesão interna: a bela forma apresenta-se como uma totalidade cuja constituição objetiva (objektive Beschaffenheit) se mostra imediatamente como resultado das relações entre suas partes, de maneira que a existência de cada uma destas, exatamente tais como são, é tornada necessária por suas relações com o todo e com as outras partes, sendo cada elemento, portanto, explicado por essas relações. É esta auto-explicabilidade que, ao oferecer ao intelecto, no campo mesmo do sensível, uma ocupação absolutamente digna de sua natureza e a ela adequada, convida-o irresistivelmente a permanecer neste campo, na medida em que o desobriga a abandoná-lo em direção ao das meras abstrações, a fim de exercer-se de forma plena. Ao invés de observá-las (beobachten), o que fazemos com vistas ao

\footnotetext{
${ }^{19}$ Idem, p. 130: "Die Formen eines solchen Bildes sind einfach und ununterbrochen und in dieser Einheit mannigfaltig, und dadurch sind sie harmonisch; ebenso wie ein süßer und angenehmer Ton durch Körper hervorgebracht wird, deren Teile gleichförmig sind. Durch die Einheit und Einfalt wird alle Schönheit erhaben, so wie es durch dieselbe alles wird, was wir wirken und reden: denn was in sich groß ist, wird, mit Einfalt ausgeführt und vorgebracht, erhaben. "Na versão apresentada, o grifo em formas é meu.

${ }^{20}$ SCHILLER, F. Kallias oder Über die Schönheit - Briefe an Gottfried Körner, in Sämtliche Werke, Bd. V, München, Deutscher Taschenbuch Verlag, 2004, p.396, carta de 8 de fevereiro de 1793: "Alle Vorstellungen sind ein Mannigfaltiges oder Stoff; die Verbindungsweise dieses Mannigfaltigen ist seine Form".

${ }^{21}$ Idem, p.403, carta de 18 de fevereiro de 1973: "Schön also heißt eine Form, die sich selbst erklärt; sich selbst erklären heißt aber hier, sich ohne Hilfe eines Begriffs erklären.”
} 
conhecimento, diz Schiller, “deixamo-nos convidar pelas próprias coisas a representálas. Nós as meramente contemplamos"22. É esta mesma conjunção de interesses entre sensibilidade e entendimento que Schiller compreenderá, cerca de dois anos mais tarde, sob a expressão forma viva (lebende Gestalt), pela qual designa, nas Cartas Estéticas o próprio fenômeno da beleza. Nesta conciliam-se o interesse pelo múltiplo, próprio do impulso sensível, com o interesse pela unidade, próprio do impulso formal. O fim último deste último interesse, por sua vez, é designado genericamente como Gestalt ("tanto no sentido próprio como no não próprio", diz o autor), com o que se põe manifesto que Schiller utiliza-se do termo essencialmente no sentido da noção abstrata de forma ${ }^{23}$.

Gestalt e Form são também termos que desempenham importante papel no terceiro livro de O Mundo como Vontade e como Representação I, aparecendo freqüentemente e em sentido semelhante ao que possuem em Schiller e Winckelmann. O compromisso da estética schopenhaueriana com a noção de forma deriva originariamente da própria doutrina das ideias platônicas, que fornece a base, senão desta mesma estética, pelo menos de sua fundamentação metafísico-filosófica. De fato, Schopenhauer designa ali reiteradamente as ideias platônicas como formas (imutáveis, arquetípicas eternas, etc... $)^{24}$ de todos os fenômenos. Claro está que tais formas platônicas, em virtude de sua independência em relação ao espaço e ao tempo, não podem ser identificadas com as formas sensíveis de falam Schiller e Winckelmann. Isto porém, não impede que estas últimas possam atuar como representantes, no plano da sensibilidade, das formas platônicas eternas, funcionando, portanto, como facilitadoras da passagem do modo de representação sujeito ao princípio de razão suficiente ao da contemplação estética da ideia.

É também verdade que a relação entre forma sensível e contemplação estética não é necessária para Schopenhauer. Esta, exatamente por fundar-se na oposição sujeito-objeto, condição de todo representar, pode ter sua origem tanto em um polo desta oposição como em outro. Assim, o fenômeno estético pode originar-se simplesmente na disposição genial do contemplador, que se mostra capaz de contemplar

\footnotetext{
${ }^{22}$ Idem, p. 396, carta de 8 de fevereiro: "Entweder wir sind mit Absicht auf ihre Erkenntnis gerichtet: wir beobachten sie; oder wir lassen uns von den Dingen selbst zu ihrer Vorstellung einladen. Wir betrachten sie bloß".

${ }^{23}$ Cf. SCHILLER, Ueber die ästhetische Erziehung des Menschen, in einer Reihe von Briefen, in Sämtliche Werke, Bd. V, München, Deutscher Taschenbuch Verlag, 2004, Fünfzehter Brief, p.614.

${ }^{24}$ Cf. SCHOPENHAUER, A. WWV I/MVR I pp. 200 [236] (formas imutáveis), 202 [238] (formas arquetípicas), 210 [246] (forma eterna) e 219 [255] (formas essenciais e permanentes do mundo).
} 
esteticamente aquilo que o intelecto comum tende a ver apenas como mera realidade empírica. É o que ocorre, por exemplo, quando as ideias a que tal contemplação dá acesso correspondem aos níveis mais elementares de objetivação da Vontade, ou seja, o das forças da natureza. Nestes casos, com efeito, a experiência estética não é provocada propriamente por um objeto isolado ou sua reprodução artística, mas sim pelas transformações físicas que determinados objetos experimentam, ou pelas relações dinâmicas que entre eles têm lugar. Assim é que as idéias das forças que atuam no meio aquoso são mais bem expostas, não por meio de um lago tranquilo, em que a água se oferecesse à calma contemplação, mas sim pelas quedas d'água e corredeiras, bem como pelas engenhosas construções da arte hidráulica, nas quais a água, forçada violentamente a percorrer caminhos que sucessivamente a afastam do estado de repouso, desdobra diante dos olhos do contemplador todas as propriedades físicas que atuam na matéria fluida ${ }^{25}$.

Porém, na medida em que nos dirigimos aos níveis mais elevados da objetivação da Vontade, a forma sensível dos objetos contemplados torna-se cada vez mais preponderante como fator desencadeante da experiência estética. Interessante "caso de passagem" neste contexto é o da arquitetura. Muito embora Schopenhauer saliente que na arte arquitetônica o fator decisivo continua sendo o dinâmico, uma vez que as idéias expostas pela arquitetura são essencialmente as de peso, impenetrabilidade e resistência, a bela forma já tem aqui um papel não negligenciável:

Todo o exposto demonstra precisamente que a arquitetura faz efeito não apenas matematica, mas também dinamicamente, e que aquilo a falar-nos por ela não é meramente a forma e a simetria, mas antes as forças fundamentais da natureza.... A regularidade do edifício e de suas partes é produzida em certa extensão pela finalidade imediata de cada parcela na estabilidade do todo, por outro lado, serve para facilitar a visão geral e compreensão do todo; por fim, as figuras regulares contribuem para a beleza, manifestando a regularidade do espaço enquanto tal. ${ }^{26}$

Mas, na medida em que nos dirigimos aos níveis mais elevados de objetivação da Vontade, a forma ganha paulatinamente preponderância. No campo da representação escultórica do ser humano esta preponderância torna-se absoluta, e é precisamente no

\footnotetext{
${ }^{25}$ Cf. SCHOPENHAUER, A. WWV I/MVR I, § 43, p. 257 [292].

${ }^{26}$ Cf. SCHOPENHAUER, A. WWV I/MVR, § 43, p. 254 [290].
} 
tratamento estético dispensado por Schopenhauer a esta modalidade artística que sua dívida para com a estética do clacissismo alemão - e para com Winckelmann, em particular - aparece com maior nitidez. O corpo humano, diz ele - em passagem que já por seu tema, mas também por seu teor, faz claro eco às idéias de Winckelmann - é um sistema formado por partes absolutamente diversas, porém subordinadas organicamente ao todo:

Que todas essas partes estejam convenientemente subordinadas ao todo e coordenadas entre si, que conspirem harmonicamente para a exposição do todo, que nada esteja nem em excesso nem atrofiado tais são as raras condições cujo resultado é a beleza... ${ }^{27}$

“A beleza humana...”, acrescenta ele mais adiante, ,...expressa-se através da forma, e esta reside exclusivamente no espaço...”. Em seguida chega à sintética definição de beleza segundo a qual esta equivale à “....adequada objetivação da Vontade por meio de um simples fenômeno espacial", com o que se põe claramente de manifesto a estreita dependência em que sua concepção de beleza se encontra em relação ao conceito de forma sensível. As objetivações adequadas da Vontade são, como sabemos, as idéias platônicas. Estas, porém, sugere-nos o trecho recém-citado, podem, por sua vez, objetivar-se no plano da sensibilidade pelo fenômeno da beleza. As formas eternas, portanto, encontram seus representantes sensíveis nas formas belas. É o que sugere também o autor ao afirmar que o estado de pura contemplação é facilitado “...mediante a ...forma (Gestalt) multifacetada e ao mesmo tempo distinta e determinada..." de certos objetos, o que imediatamente os eleva à condição de “...representantes de suas idéias", nisto precisamente consistindo sua beleza ${ }^{28}$. Semelhantes características da bela forma, bem como seu papel como facilitadora da passagem à contemplação da ideia, são também apresentadas mais adiante da seguinte maneira:

\footnotetext{
${ }^{27}$ SCHOPENHAUER, A. WWV I/MVR I. § 45, p.261 [296]: “...der menschliche Körper ist ein höchst kombinirtes System ganz verschiedener Theile, deren jeder ein dem Ganzen untergeordnetes, aber doch auch eigenthümliches Leben, vita propria, hat: daß nun alle diese Theile gerade auf die gehörige Weise dem Ganzen untergeordnet und einander nebengeordnet seien, harmonisch zur Darstellung des Ganzen konspiriren, nichts übermäßig, nichts verkümmert sei; — dies Alles sind die seltenen Bedingungen, deren Resultat die Schönheit, der vollkommen ausgeprägte Gattungscharakter ist".

${ }^{28}$ SCHOPENHAUER, A., WWV I/MVR I., § 39, pp.236-237 [272]: "Es ist schon oben bemerkt, daß das Versetzen in den Zustand des reinen Anschauens am leichtesten eintritt, wenn die Gegenstände demselben entgegenkommen, d.h. durch ihre mannigfaltige und zugleich bestimmte und deutliche Gestalt leicht zu Repräsentanten ihrer Ideen werden, worin eben die Schönheit, im objektiven Sinne, besteht".
} 
Uma coisa é mais bela que outra quando facilita a pura consideração objetiva, vem-lhe ao encontro, sim, como que compele a isso: então a nomeamos muito bela. Este é o caso, primeiro, quando algo isolado exprime de modo puro a ideia de sua espécie mediante proporção bem distinta, puramente determinada, inteiramente significativa de suas partes, reunindo em si todas as exteriorizações possíveis da Ideia de sua espécie e a manifestando com perfeição: justamente por aí a coisa isolada facilita bastante ao espectador a transição para a Ideia, o qual atinge assim o estado de intuição pura ${ }^{29}$.

Vê-se, portanto, que a ideia de bela forma implica para o autor a das mútuas e harmônicas relações entre suas partes e a de cada uma delas com o todo. Pensa-se aqui o claro copertencimento destas partes no seio de uma unidade simples e imediatamente apreensível pela intuição. Trata-se, portanto, daquela mesma coerência interna e autoreferencialidade que Schiller caracteriza como a auto-explicabilidade da beleza. O objeto belo, diz Schopenhauer, valendo-se de forma sugestiva da mesma expressão utilizada por Schiller nas cartas do projeto Kallias, $\operatorname{convida-nos}^{30}$ à experiência estética exatamente porque tudo na forma bela remete imediatamente apenas a ela mesma, ou, dito com mais rigor: todos os seus elementos podem ser apreendidos (e, dir-se-ia, pedem para sê-lo) apenas segundo as relações que mantém com os outros elementos e com a unidade simples de que fazem parte. Na medida em que se deixa convidar pela bela forma, persuadindo-se a permanecer no âmbito das múltiplas relações que ela em si encerra, o intelecto é também dissuadido de seguir o caminho que lhe é costumeiro e natural, o de perceber esta forma como pertencente a um objeto empírico que por sua vez encontra-se inserido em uma realidade empírica governada por leis causais. Em deixando-se convidar desta maneira, põe-se então ele a um passo da pura contemplação da Ideia.

O papel desempenhado pela forma nessa passagem da consideração empírica à estética, bem como a relação entre forma sensível e ideia platônica, são assuntos mais claramente explicitados no primeiro dos complementos ao Terceiro Livro da obra máxima de Schopenhauer, ou seja, no capítulo XXIX do segundo volume da mesma. Ali, a apreensão da ideia figura como quarto e mais elevado patamar de uma escala em que as diferentes formas de conhecimento intuitivo são apresentadas segundo seus graus de objetividade, correspondendo estes, em relação inversa, a outros tantos graus de

\footnotetext{
${ }^{29}$ SCHOPENHAUER, A. WWV I/MVR I., § 41, p.248 [283-284]. Grifo meu.

${ }^{30}$ A expressão pode ser encontrada, no mesmo sentido nas páginas 232 [268], 237 [273] e 246 [282] de WWV I/MVR I.
} 
participação da vontade individual. Tem-se primeiramente o grau de absoluta servidão da intelecto à vontade do sujeito, no qual o objeto é conhecido na sua imediata relação a essa vontade, podendo, por isso, dela tornar-se motivo. Em seguida, tem-se o patamar em que o intelecto interessa-se pelo conhecimento das relações que as coisas mantém, não mais diretamente com o sujeito, mas sim entre si, o que, como sabemos, é levado a efeito por meio da noção de causalidade. Este tipo de conhecimento, porém, processase ainda “...em prol da completude ..." daquele primeiro tipo de conhecimento (...eben zum Behuf der Vollständigkeit dieser Erkenntni $\beta . ..)^{31}$, pois, como expressa o capítulo 33 do primeiro tomo de $O$ Mundo..., “....todo conhecimento conforme o princípio de razão encontra-se numa relação próxima ou distante com a Vontade 244 ..."32. Está claro que essa distância poderá ser bastante grande, como ocorre, por exemplo, nas chamadas ciências puras, campo em que as relações do conhecimento com a Vontade podem beirar o intangível (que relação com os interesses práticos do homem terá, digamos, o conhecimento dos movimentos planetários ou da digestão dos invertebrados?). Por isso mesmo, Schopenhauer pode classificar este tipo de conhecimento como ponte de transição para o conhecimento puramente objetivo, ou artístico ${ }^{33}$. Vale a pena deixar que o próprio Schopenhauer o descreva:

Quando, justamente, de um objeto são apreendidas imediatamente muitas e diversificadas relações, aparece então, a partir destas, sempre mais claramente, a essência propriamente particular deste objeto, a qual se constitui, portanto, paulatinamente, a partir de puras relações, muito embora essa essência seja totalmente distinta daquelas relações. 34 (grifos meus).

Visto que já se abandonou o campo das relações entre as coisas, essas relações a partir das quais se constitui a essência propriamente particular do objeto, ou seja, a

\footnotetext{
${ }^{31}$ SCHOPENHAUER, A. WWV II/MVR II, Kap. XXIX, p. 413: "Wie also daselbst ... ausgeführt worden, erkennt der im Dienste des Willens, also in seiner natürlichen Funktion thätige Intellekt eigentlich bloße Beziehungen der Dinge: zunächst nämlich ihre Beziehungen auf den Willen, dem er angehört, selbst, wodurch sie zu Motiven desselben werden; dann aber auch, eben zum Behuf der Vollständigkeit dieser Erkenntniß, die Beziehungen der Dinge zu einander".

${ }^{32}$ SCHOPENHAUER, A. WWV I/MVR I, §33, p. 208 [244].

${ }^{33}$ SCHOPENHAUER, A. WWV II/MVR II, Kap. XXIX, p. 414: "Offenbar geschieht die Auffassung der Beziehungen, welche die Dinge zu einander haben, nur noch mittelbar im Dienste des Willens. Sie macht daher den Uebergang zu dem von diesem ganz unabhängigen, rein objektiven Erkennen: sie ist die wissenschaftliche, dieses die künstlerische".

${ }^{34}$ Idem, ibidem: "Wenn nämlich von einem Objekte viele und mannigfaltige Beziehungen unmittelbar aufgefaßt werden; so tritt aus diesen, immer deutlicher, das selbsteigene Wesen desselben hervor und baut sich so aus lauter Relationen allmälig auf; wiewohl es selbst von diesen ganz verschieden ist".
} 
Ideia, não podem ser senão as relações do objeto consigo mesmo, as relações entre suas partes e destas com o todo. Como bem o diz Schopenhauer, trata-se das muitas e diversificadas relações de um objeto, e não daquelas que o ligam a qualquer outro objeto ou ao mundo circundante. Tampouco podem ser estas relações entre as partes constitutivas do objeto compreendidas como de natureza físico-mecânica ou biológica, o que já envolveria reflexão e nos colocaria de novo no campo de atuação do princípio de causalidade. Trata-se, como também explicita o autor, de relações apreendidas imediatamente, o que só pode significar que se esteja aludindo aqui à mera configuração do objeto como simples fenômeno espacial, mediante a qual, como já vimos, se dá a adequada objetivação da Vontade, no fenômeno da beleza. De fato, logo adiante dirá Schopenhauer constituírem forma e cor exatamente o imediato na apreensão intuitiva da ideia, cabendo evidentemente à forma o papel de portadora daquelas relações múltiplas e variadas de cuja apreensão depende a experiência do belo ${ }^{35}$.

Ao passar-se da apreensão empírica das relações causais entre os objetos à apreensão imediata das relações inerentes a um objeto - vale dizer, das relações que constituem sua forma -, a participação da Vontade torna-se a mais tênue possível, embora Schopenhauer não nos esclareça sobre no que exatamente consiste essa participação subsistente ${ }^{36}$. Mas é compreensível a admissão de uma qualquer relação entre a apreensão da forma e a Vontade, uma vez que a primeira ainda pressupõe uma das formas da sensibilidade: o espaço, o qual permanece sendo campo de atuação de uma das modalidades do princípio de razão suficiente ${ }^{37}$.

Exatamente por isso, a apreensão da forma não pode ser identificada com o conhecimento da Ideia, já que a esta não pertencem nem temporalidade nem espacialidade. A apreensão das múltiplas relações formais, porém, representa o umbral que dá acesso ao campo do puro conhecimento das ideias, é o ponto de apoio ao

\footnotetext{
${ }^{35}$ SCHOPENHAUER, A., WWV II/MVR II, Kap. XXIX, p. 415. Em relação às cores, diz Schopenhauer (WWV I/MVR I, § 38, p. 235 [271]) que elas “...despertam de imediato um prazer vivaz...”, devido ao fato de que sua apreensão - como a da luz, em geral - não tem efeito imediato sobre a Vontade, constituindo-se, portanto, em um análogo do conhecimento puro. Isto, porém, ainda não nos permite atribuir-lhes beleza. Mais adiante (WWV I/MVR I, §45, p. 266 [301]) afirma que as cores podem contribuir bastante para a beleza, o que, podemos concluir, pressupõe que já esteja associada à bela forma, realçando-a e acrescentando à sua apreensão aquele puro prazer que por si mesmas despertam.

${ }^{36}$ SCHOPENHAUER, A. WWV II/MVR II, Kap. XXIX, p. 414: "Bei dieser Auffassungsweise wird zugleich die Dienstbarkeit des Intellekts unter dem Willen immer mittelbarer und geringer".

${ }^{37}$ As relações espaciais e temporais, como se sabe, estão, separadamente, sob a jurisdição do princípio de razão do ser, enquanto que a causalidade, na qual espaço e tempo são unidos, corresponde ao princípio de razão do devir, que é abandonado quando da apreensão da forma.
} 
derradeiro salto pelo qual o intelecto abandona definitivamente todas as relações para atingir a máxima objetividade e contemplar o verdadeiro caráter das coisas, jacente para além de tempo e espaço. A forma esteticamente intuída não é a ideia, insiste Schopenhauer, mas isso não a impede de ser seu meio (Medium) de expressão ${ }^{38}$. Dir-seia que, assim como em Platão a ideia do belo é a única, dentre as mais superiores, a possuir um símile sensível - nomeadamente, na beleza das coisas individuais ${ }^{39}$-, para Schopenhauer, a beleza sensível torna-se o símile das ideias em geral. A ideia se expressa na forma. É neste sentido que ele cita o neoplatônico Olimpiodoro, cuja sentença a esse respeito ele assim traduz: "A ideia, em si inextensa, outorgou a forma (Gestalt) à matéria, tendo primeiramente recebido desta a extensão..." ${ }^{40}$. Surgindo ao contemplador como resultado da soma (Resultat der Summe) das relações formais, a ideia é na verdade o ponto de enraizamento (Wurzelpunkt) dessas relações, pois é ela que determina a totalidade das relações do objeto estético ${ }^{41}$.

Por isso a contemplação da ideia é o pressuposto de toda criação artística. O gênio artístico não cria a bela forma a partir da imitação das formas sensíveis que se lhe deparam como modelo: a partir da contemplação das formas sensíveis, passa ele à intelecção pura daquela realidade ideal que as determina, e é esta realidade que lhe serve efetivamente de modelo. E isso explica que sua criação muitas vezes exceda em beleza tudo aquilo que a natureza pôde oferecer como modelo.

Note-se que o estabelecimento do ideal, em detrimento do empiricamente real, como fonte da criação artística, é um princípio estético que já as Reflexões de Winckelmann atribuíam aos gregos e recomendavam aos modernos. Os produtos da mais bela natureza, que os primeiros tinham sempre à disposição em seus ateliês e nos

\footnotetext{
${ }^{38}$ SCHOPENHAUER, A. WWV II/MVR II, Kap. XXIX, p. 415: "Sogar Form und Farbe, welche, in der anschauenden Auffassung der Idee, das Unmittelbare sind, gehören im Grunde nicht dieser an, sondern sind nur das Medium ihres Ausdrucks".

39 "Pois bem:...", afirma Sócrates a Fedro, no diálogo platônico de mesmo nome, “...as imitações terrenas da justiça e da sabedoria e todas as outras qualidades da alma não têm fulgor em suas imagens terrestres.... Mas a beleza era visível em todo o seu esplendor... ....ela [a beleza] brilhava entre todas aquelas Ideias Puras, e na nossa estada na Terra ela ainda ofusca com seu brilho todas as outras coisas. A visão é ainda o mais sutil de todos os nossos sentidos. Mas não poderia perceber a sabedoria. Despertaria amores veementes se oferecesse uma imagem tão clara e distinta quanto aquelas que podíamos contemplar para além do céu. Somente a beleza tem essa ventura de ser a coisa mais perceptível e enlevadora" (PLATÃO. Diálogos. Rio de Janeiro: Ed. Globo, 1960, tradução de Jorge Paleikat, p. 223).

40 SCHOPENHAUER, A. WWV II/MVR II, Kap. XXIX, p. 415: "die Idee, an sich unausgedehnt, ertheilte zwar der Materie die Gestalt, nahm aber erst von ihr die Ausdehnung an".

${ }^{41}$ Cf. op. cit, p. 414.
} 
ginásios esportivos, eram-lhes, diz o autor, apenas o ponto de partida para a concepção e reprodução de belezas bem mais excelsas:

Os conhecedores e imitadores das obras gregas encontram em suas obras-primas não apenas a mais bela natureza, mas ainda mais que a natureza, ou seja, certas belezas ideais que, como ensina um antigo comentador de Platão, são produzidas a partir de imagens engendradas apenas no intelecto. ${ }^{42}$

Apenas a partir de conceitos de beleza que se elevam "acima da forma comum da matéria", puderam os gregos criar as belezas ideais que as imagens em mármore de seus deuses exibem: pois o surgimento de um Apolo de Belvedere não é explicável a partir da mera imitação da natureza. Seguiam, pois em suas sublimes criações, não o que a natureza fortuita e casualmente logrou engendrar, mas sim “...a verdade da natureza" 43 .

Também Schopenhauer, no capítulo 45 de sua obra capital, perguntará de forma retórica se alguma vez a natureza haveria produzido um ser humano perfeitamente belo $^{44}$. Porém, o objetivo da arte escultórica não pode ser outro senão a produção desta perfeita beleza, do que então conclui que a escultura não pode restringir-se à mera reprodução daquilo que a natureza efetivamente criou, por mais beleza que suas criaturas contenham, mas deve ocupar-se com a produção artística daquilo que ela tentou criar. O que possibilitou que o gênio grego encontrasse o tipo primordial da forma humana (“den Urtypus der menschlichen Gestalt”) terá sido, diz o filósofo em trecho de claríssima inspiração winckelmanniana, uma espécie de antecipação, pela qual o artista compreendia os pensamentos ocultos da natureza:

Antecipação que, no autêntico gênio, é acompanhada de um tal grau de clarividência, que ele reconhece nas coisas isoladas a Idéia, como que ENTENDE A NATUREZA EM SUAS MEIAS PALAVRAS, e, então exprime puramente o que ela apenas balbuciava. Ele imprime no mármore duro a beleza da forma que a natureza malogrou em milhares de tentativas,

\footnotetext{
${ }^{42}$ WINCKELMANN, J. "Gedanken über die Nachahmung der griechischen Werke in der Malerei und Bildhauerkunst", op. cit., p. 3: "Die Kenner und Nachahmer der griechischen Werke finden in ihren Meisterstücken nicht allein die schönste Natur, sondern noch mehr als Natur, das ist, gewisse idealische Schönheiten derselben, die, wie uns ein alter Ausleger des Plato lehret, von Bildern bloß im Verstande entworfen, gemacht sind". O comentador de Platão é outro neoplatônico: Proclo.

${ }^{43}$ Idem, p.8.

${ }^{44}$ Cf. SCHOPENHAUER, A. WWV I/MVR I, §45, p. 261 [297].
} 
colocando-a diante dela e lhe brada: "Eis o que querias dizer!". Para em seguida ouvir a concordância do conhecedor: "Era isso mesmo!" 45

Tais reflexões parecem-me suficientes pelo menos para fazer ressaltar algumas notáveis proximidades entre o pensamento estético de Schopenhauer e a estética do neoclassicismo alemão. Mas é preciso lembrar que a noção de bela forma - inclusive em sua conexão com o pressuposto de uma realidade ideal como origem e objeto da arte -, é, como já indicamos, apenas um dos muitos caminhos pelos quais se pode seguir tal relação de proximidade. Se corroborada e aprofundada ainda por outros caminhos, esta relação provavelmente nos levará a uma interessante conclusão, da qual talvez surja uma nova pergunta, ainda mais interessante, e é com a explicitação de ambas que gostaria de encerrar este trabalho. A conclusão será a de que aquilo que costumeiramente chamamos de estética schopenhaueriana não corresponde exatamente a uma estética original, mas sim a uma interpretação filosófico-metafísica de um conjunto de concepções já estabelecido à época em que o filósofo escreve sua obra capital, nomeadamente, as pertencentes ao classicismo alemão, especialmente como esta se apresenta em sua vertente weimarana e em seu precursor (Winckelmann). Já a pergunta - em cuja resposta o autor destas linhas não se vê em condições sequer de arriscar um palpite - soaria mais ou menos assim: dada a importância que a estética possui no pensamento de Schopenhauer, em que medida essa vinculação teórica poderia nos auxiliar na compreensão do sentido e da constituição histórica da doutrina schopenhaueriana das ideias platônicas?

\section{Referências bibliográficas}

MEIER, A. Klassik-Romantik. Stuttgart: Reclam, 2008.

PLATÃO. Diálogos. Rio de Janeiro: Ed. Globo, 1960.

SCHILLER, F. Kallias oder Über die Schönheit - Briefe an Gottfried Körner. In: Sämtliche Werke. Bd. V. München: Deutscher Taschenbuch Verlag, 2004.

Ueber die ästhetische Erziehung des Menschen in einer Reihe von Briefen. In: Sämtliche Werke. Bd. V. München: Deutscher Taschenbuch Verlag, 2004.

\footnotetext{
${ }^{45}$ Idem, ibidem.
} 
SCHOPENHAUER, A. Schopenhauers Sämtliche Werke. Hrsg. von Paul Deussen. München: Piper Verlag, 1911-1926. In: CD-ROM Schopenhauer im Kontext, Werkausgabe I. Berlin: Karsten Worm, 2001.

Die Welt als Wille und Vorstellung I. In: Schopenhauers Sämtliche Werke. München: Piper Verlag, 1911-1926.

Die Welt als Wille und Vorstellung II. In: Schopenhauers Sämtliche Werke. München: Piper Verlag, 1911-1926.

Parerga und Paralipomena. In: Schopenhauers Sämtliche Werke. München: Piper Verlag, 1911-1926

O mundo como vontade e como representação I. Trad. Jair Barboza. São Paulo: Editora Unesp, 2005.

. Metafísica do Belo. Trad. Jair Barboza. São Paulo: Ed. Unesp, 2001.

WINCKELMANN, J. Gedanken über die Nachahmung der griechischen Werke in der Malerei und Bildhauerkunst. In: Winckelmanns Werke in einem Band. Berlin und Weimar: Aufbau, 1969.

Nachfolger, 1964.

Geschichte der Kunst des Altertums. Weimar: Verlag Hermann Böhlaus

Recebido: 25/12/14

Received: $12 / 25 / 14$

Aprovado: 07/03/15

Approved: 03/07/15 